\title{
Construction of Transgenic Pea Lines with Modified Expression of Diamine Oxidase and Modified Nodulation Responses with Exogenous Putrescine
}

\author{
J.-P. Wisniewski and N. J. Brewin \\ John Innes Centre, Norwich, NR4 7UH, U.K. \\ Accepted 12 May 2000.
}

\begin{abstract}
Diamine oxidase (DAO) might influence pea nodule development either by regulating the peroxide-driven crosslinking of glycoproteins in the infection thread matrix or by modifying the metabolism of diamines and polyamines in host cells. Transformed lines of pea (Pisum sativum) with the coding sequence for DAO (PSAO-1) in sense orientation behind a tissue-specific promoter (pENOD12A) showed strong co-suppression of DAO activity in extracts from nodules and epicotyls, whereas the antisense constructs were relatively unaffected. No difference in nodule number was observed between transformed lines and controls, suggesting that DAO does not normally have an essential role in nodule initiation. However, lines showing cosuppression of DAO were less sensitive to the inhibitory effects of exogenous putrescine and less active in the crosslinking of matrix glycoprotein, indicating that putrescinederived products of DAO activity could retard nodule development. Inoculation of co-suppressed lines with Rhizobium strain B661 (a lipopolysaccharide-defective mutant) resulted in more extreme impairment of nodule development and nitrogen fixation capacity, relative to lines with normal levels of DAO, which suggests that DAO may serve to reduce the endogenous level of inhibitory diamines or polyamines in nodules under physiological stress. We conclude that the most critical role of DAO in pea nodule development is apparently in the regulation of diamine levels in host tissues.
\end{abstract}

Additional keywords: extensin, legume, Rhizobium leguminosarum bv. viciae, symbiosis, transformation.

Diamine oxidases (DAO) are copper-containing enzymes widely distributed in microbial, plant, and animal systems. DAO catalyzes the oxidative deamination of diamines such as putrescine with the formation of the corresponding aldehyde along with hydrogen peroxide and ammonia. Some plant DAOs have been purified and characterized, especially from leguminous species, in which DAO occurs at high concentra-

Corresponding author: N. J. Brewin; Telephone: +44 01603 450273; Fax: +44 01603 450045; E-mail: brewin@bbsrc.ac.uk

Current address of J.-P. Wisniewski: Aventis CropScience, BP 9163, 69263, Lyon 09, France. tion. The enzymes are loosely associated with plant cell walls, and high activity has been reported in the middle lamellar region and in the vascular parenchyma cells of pea seedling roots, as well as in lignified tissues (Medda et al. 1995; Wisniewski et al. 2000). In situ hybridization studies indicate that DAO transcript is abundant in all infected tissue of pea nodules, both in the invasion zone and in the host cells that support nitrogen-fixing bacteroids (Wisniewski et al. 2000).

The function of DAO may be due in part to the modulation of the level of polyamines (PAs) and in part to $\mathrm{H}_{2} \mathrm{O}_{2}$ production through the oxidation of diamines. In chick-pea, the level of diamines is apparently controlled by catabolism rather than synthesis (Torrigiani and Scoccianti 1995), i.e., through oxidation by DAO. Hydrogen peroxide, the product of this reaction, can be utilized by peroxidase enzymes, thus leading to the modulation of cell wall plasticity. Spatial and temporal correlations of DAO and peroxidase activity have suggested a role for DAO in cross-linking of proteins and polymerization of monolignols (Angelini et al. 1990; Moller and McPherson 1998). Cross-linking of proteins like extensins occurs not only during normal plant growth but also in response to stress and wounding. The activity of DAO is modulated by wounding and other stress factors (Maccarrone et al. 1997; Smith and Barker 1998). Recently, it has been shown that diamines can induce production of activated oxygen species in the apoplastic space of tobacco cells and thus can take part in the plant defense reaction (Allan and Fluhr 1997). Thus, DAO might have a role in plant growth and plant defense reactions by oxidizing diamines.

The role of DAO in modulating the titer of polyamines in planta is also likely to be of primary importance. In plants, PAs have been implicated in many processes including growth and development, stress responses, and senescence (for a review, see Bouchereau et al. 1999). At cellular $\mathrm{pH}$ values, they are positively charged and can interact with DNA, phospholipids, and proteins. In Conyza canadensis, elevated levels of putrescine-generating enzymes and increased tissue concentration of PAs were correlated with oxidant resistance of the plant (Ye et al. 1997). In addition, high cellular levels of putrescine, the obligate precursor of PAs, have been associated with plant resistance to pathogens (Pinon et al. 1999). PAs also seem to play a role in plant-microbe symbiosis. Feeding peas with PAs at concentration below $1 \mathrm{mM}$ has been shown to increase the frequency of arbuscular mycorrhizal infection 
(El Ghachtouli et al. 1995). On the other hand, using DFMO ( $\alpha$-DL-difluoromethylornithine) a specific inhibitor of putrescine biosynthesis, the same authors showed that mycorrhizal infection is strongly reduced (El Ghachtouli et al. 1996). Similarly, the efficiency of the goat's rue symbiosis with $R h i$ zobium galegae was reported to be modulated in the presence of diamines and PAs (Vassileva and Ignatov 1999).

We are interested in the mechanisms involved in the plantmediated control of root colonization by Rhizobium spp. and infection thread growth. Bacteria growing within the infection thread are embedded in a plant-derived matrix containing an extensin recognized by monoclonal antibody MAC265 (Brewin et al. 2000). In a previous study, we showed that this matrix glycoprotein (MGP) could be cross-linked under oxidative conditions implicating peroxidase and DAO (Wisniewski et al. 2000) and we suggested that the control of MGP cross-linking could be an important factor controlling the development of the infection thread. To investigate the role of DAO in nodule development, we therefore generated transgenic pea lines with modified DAO activity. A number of lines with reduced DAO activity were obtained as a result of co-suppression and the properties of these lines are described. The results suggest that DAO does not have an essential role in nodule initiation but it may function to regulate the levels of diamines and PAs in host cells.

\section{RESULTS}

\section{Screening of transgenic lines for expression of DAO.}

In an attempt to restrict perturbations in DAO expression to processes associated with infection thread formation, the coding sequence for PSAO-1 was introduced in sense (S) and antisense (AS) orientation behind the early nodulin promoter ENOD12A (Fig. 1). Transformation of 200 pea seedlings with the $\mathrm{S}$ construct eventually yielded five $\mathrm{T}_{0}$ polymerase chain reaction (PCR)-positive lines. For only two lines, named S1 and S2, was the transgenic status stable and found in the following generation. Peas transformed with the AS construct gave more putative $\mathrm{T}_{0}$ transformants. Two stables lines, AS1

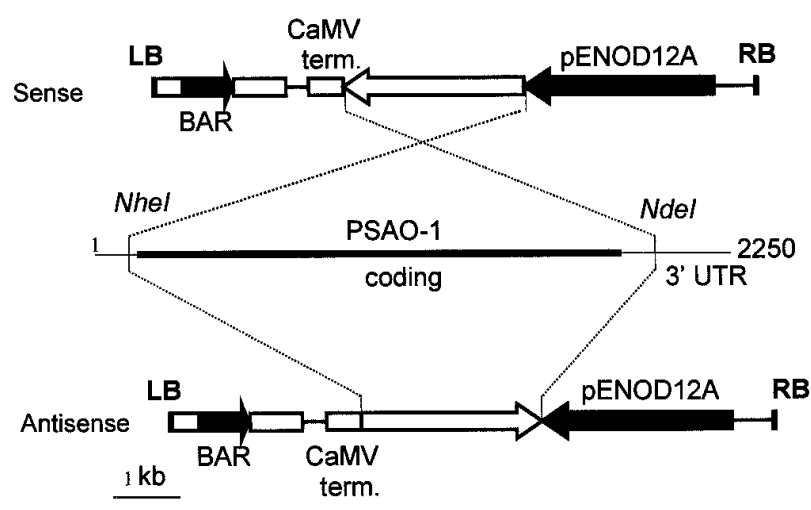

Fig. 1. Physical maps of sense and antisense constructs used to transform pea. LB and RB: left and right borders of T-DNA, respectively. The 2.09-kb NheI-NdeI fragment of the pea diamine oxidase (DAO) cDNA (PSAO-1) was inserted behind the promoter of the pea early nodulin gene ENOD12A and terminated with the Cauliflower mosaic virus (CaMV) terminator. The BAR gene under the control of the NOS promoter and terminator was used as selective marker. and AS2, were selected and studied further. $\mathrm{T}_{1}$ seeds of the four selected lines were inoculated with the wild-type (WT) Rhizobium strain 3841. Three weeks after inoculation, the number of nodules was determined, and the specific DAO activity in nodule extracts was quantified. The enzymatic activity in nodules of the AS lines was unaffected, compared with the WT plants (Fig. 2). On the other hand, the DAO activity was greatly reduced in nodules of the two $\mathrm{S}$ lines. Despite this striking difference, no real difference in nodulation ability of the plants was noticed.

To investigate whether the absence of DAO activity was due to the absence of protein, or due to any inhibitory problem, immunodetection of DAO was undertaken with the monoclonal antibody LM4. Figure 3 shows a very good correlation between the decreased DAO activity and the absence of protein antigen in the $S$ lines. Thus, the $S$ lines apparently showed suppression of the transgene as well as the native DAO homologue, a phenomenon characteristic of cosuppression. However, some lines, e.g., S1.1 and S1.3, yielded negative results with PCR, indicating segregants, and in these cases no effect on DAO activity or antigenicity was observed.

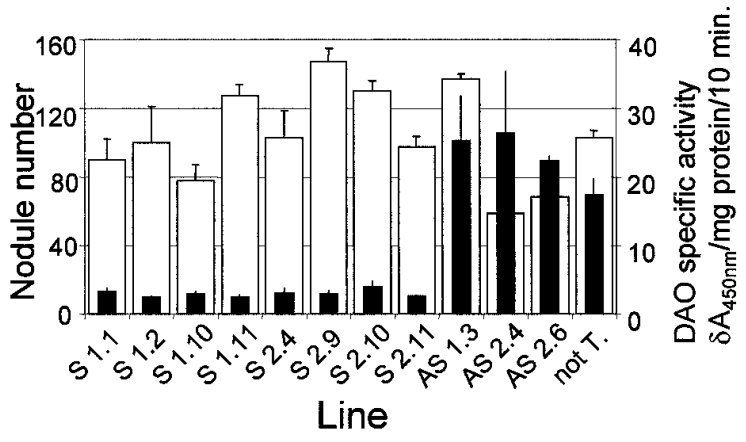

Fig. 2. Screening of transgenic lines for expression of diamine oxidase (DAO). $\mathrm{T}_{1}$ seedlings of transgenic lines were inoculated with cultures of Rhizobium strain 3841. Nodule number and DAO activity in nodules were quantified at 17 days post inoculation. S1.1, S1.2, S1.10, S1.11: $\mathrm{T}_{1}$ seedlings derived from the first sense line (S1). S2.4, S2.9, S2.10, S2.11: $\mathrm{T}_{1}$ seedlings from second sense line (S2). AS1.3, AS1.3: $\mathrm{T}_{1}$ seedlings from first antisense line (AS1). AS2.4, AS2.6: $\mathrm{T}_{1}$ seedlings from second antisense line (AS2). Not T: untransformed plants (polymerase chain reaction negative). Nodule number (white bar) and DAO activity (black bar) are expressed as mean values per plant: standard errors are for at least seven or three replicates, respectively.

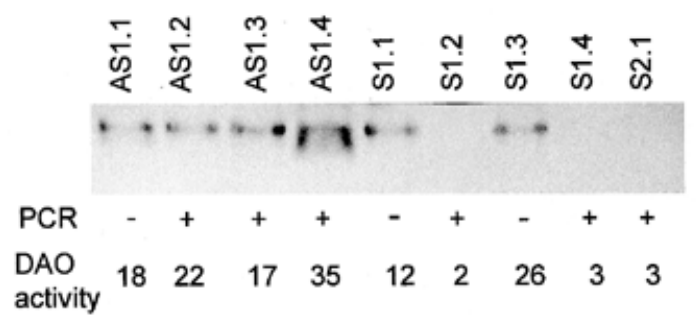

Fig. 3. Analysis of transgenic lines by diamine oxidase (DAO) antigenicity, genomic polymerase chain reaction (PCR) and DAO-specific activity. Upper lane: Western blot (immunoblot) of pea nodule extracts $(30 \mu \mathrm{g})$ immunostained with LM4 monoclonal antibody. Center lane: verification of transformed status of lines by PCR analysis (+, transformed; -, untransformed). Lower lane: DAO-specific activity in nodules $\left(\delta A_{450}\right.$ per $\mathrm{mg}$ of protein per $\left.10 \mathrm{~min}\right)$. 
Analysis of the co-suppression effect in the $S$ lines.

To see whether the under-expression of the $\mathrm{S}$ lines was limited to root tissues and linked to the expression of the ENOD12 promoter, the DAO activity was quantified in sev-
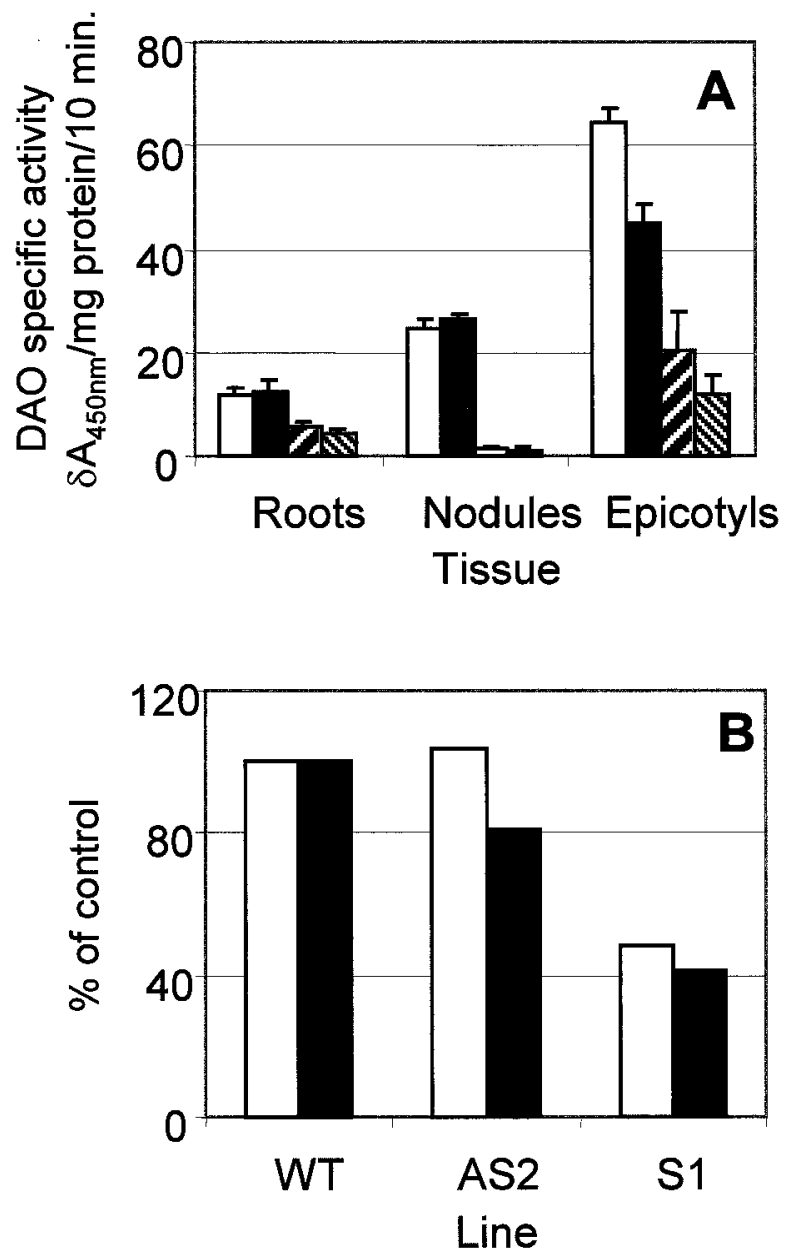

Fig. 4. Analysis of the specific enzyme activity and mRNA expression of diamine oxidase (DAO) in transgenic lines. A, Quantification of DAO-specific activity in different tissues of transgenic plants. Values are expressed as mean and standard error of at least three replicates. Open bar, wild type (WT); black, AS2.6; left hatch, S1.10; right hatch, S2.10. $\mathbf{B}$, Relative abundance of DAO enzyme activity and mRNA transcript in 10-day-old pea roots for AS2.6 and S1.10, each expressed as percentage of control. Open bar, enzyme specific activity; filled bar, level.

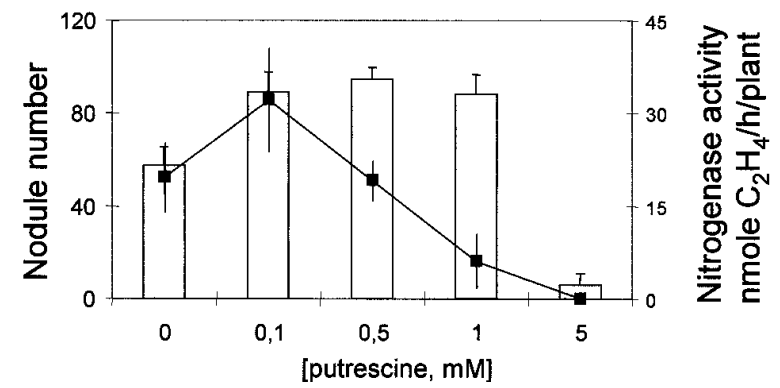

Fig. 5. Effect of exogenous putrescine on nodulation (bars) and nitrogen fixation (line) for wild-type (WT) plants and WT bacteria. Nodule number per plant and acetylene reduction activity were quantified 17 days post inoculation and are expressed as mean and standard error of at least seven or five replicates, respectively. eral tissues of transgenic and WT plants. The enzyme activity was almost unaffected in all tissues derived from plants of the AS2 lines (Fig. 4A). On the other hand, the DAO activity in $\mathrm{S} 1$ and S2 lines was always decreased in all the tissues analyzed (from $50 \%$ in roots, to $90 \%$ in nodules). The abundance of DAO mRNA was quantified by reverse transcription (RT)PCR with primers designed from the coding sequence of PSAO-1, thus detecting both transgenic and native DAO mRNA. A small reduction in the amount of DAO mRNA was detected in the roots of the AS2 line (Fig. 4B). On the other hand, a decrease of approximately $60 \%$ was observed in roots of the S1 line, correlated with the decrease of the enzyme activity. Similarly, there was a decrease of ENOD12A mRNA in nodules of S lines (data not shown).

\section{Effect of exogenous putrescine on nodule development.}

Because the co-suppressed lines were shown to be unaffected in nodulation ability, we tested the effect on the nodulation process of exogenous putrescine added to the growth medium of WT peas in a range from 0.1 to $5 \mathrm{mM}$. Low concentrations of putrescine (up to $1 \mathrm{mM}$ ) induced a slight increase in nodule number (Fig. 5). At $0.1 \mathrm{mM}$ concentration, the nitrogenase activity was more than $50 \%$ increased while, at $1 \mathrm{mM}$, nitrogenase activity was significantly reduced and the nodules were almost white. A concentration of $5 \mathrm{mM}$ induced a drastic decrease in nodule number, but the overall growth inhibition of the plant was obvious. This concentration inhibited the overall growth of peas with a loss of turgor and necrotic spots in leaves, as previously described (Flores 1991).

\section{Reduced effect of putrescine on nodule development in co-suppressed lines.}

Since exogenous putrescine is inhibitory to nodule development, it was interesting to test the ability of the cosuppressed lines to nodulate in this stressed condition. The two $S$ lines ( $T_{2}$ generation) were cultivated on FP with 1 or 5 $\mathrm{mM}$ putrescine and then inoculated with the WT Rhizobium strain B661. WT plants and one AS line with unaffected DAO expression were also tested under the same conditions. No significant difference in nodule number was detected with 1 $\mathrm{mM}$ putrescine (Fig. 6A). However, at $5 \mathrm{mM}$ the DAO cosuppressed $\mathrm{S}$ lines developed more nodules, although these were still white. In addition, measurements of acetylene reduction activity revealed that the co-suppressed plants had a normal nitrogenase activity, compared with WT or AS lines while cultivated with $1 \mathrm{mM}$ polyamine (Fig. 6B). Thus, the reduced nitrogen fixation capacity of WT peas cultivated with exogenous putrescine at a concentration higher than $1 \mathrm{mM}$ was not observed in the DAO co-suppressed lines.

\section{Reduced nodulation capacity of co-suppressed lines with lipopolysaccharide-defective strain B661.}

We then investigated whether co-suppressed pea lines showed increased or decreased stringency in their host defense response toward incompatible inoculant strains. Mutants of Rhizobium leguminosarum bv. viciae with modifications in the structure of their lipopolysaccharides (LPS) induce ineffective pea root nodules showing a severely reduced capacity for symbiotic nitrogen fixation (Perotto et al. 1994). In these ineffective nodules, rhizobia were released into only a minority of the host cells and invasion was often associated with a host 
plant defense reaction. Inoculation of the transgenic lines with B661, one of these LPS-defective mutants, showed that the co-suppressed S line had a further delay in nodule formation (Fig. 7). Moreover, measurement of acetylene reduction activity showed that this mutant induced a further decrease in the capacity for symbiotic nitrogen fixation in this line (Fig. 8). Evidently, a reduction in nodule DAO activity had not resulted in increased tolerance of ineffective symbionts such as B661, but rather the incompatibility of this strain appeared to be further aggravated in the co-suppressed lines.

Extractability of the MGP in the presence of putrescine.

In a previous study, we showed that MGP, an extensin-like glycoprotein present in the infection thread, was insolubilized in pea roots by a phenomenon driven by peroxidase activity with $\mathrm{H}_{2} \mathrm{O}_{2}$ produced by DAO in the presence of putrescine
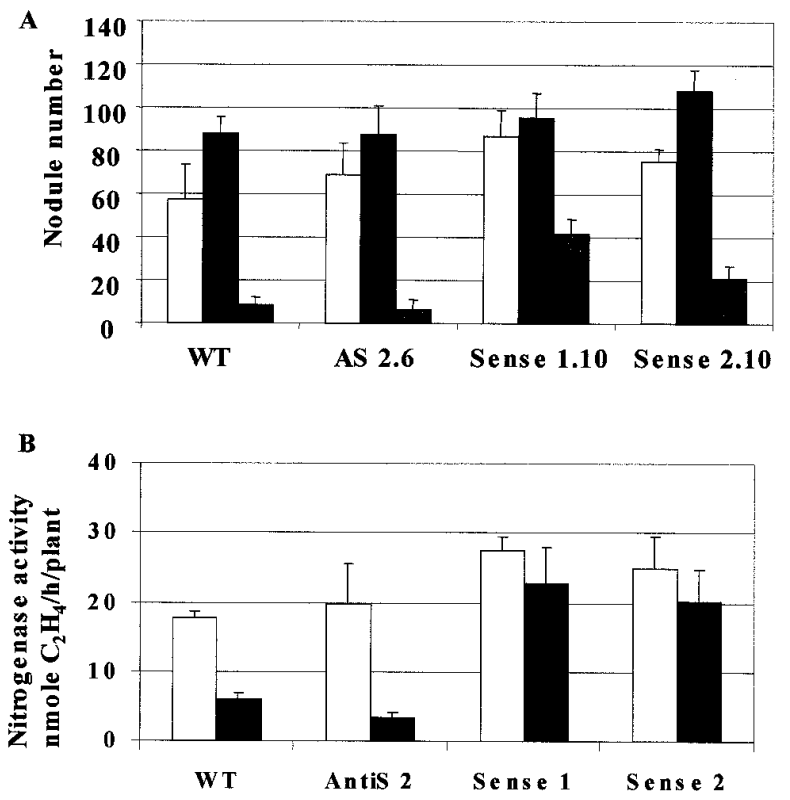

Fig. 6. Effect of exogenously added putrescine on nodulation and on nitrogen fixation in $\mathrm{T}_{2}$ transgenic lines. A, Nodule number. B, Acetylene reduction activity. Open symbols, control (FP medium); closed symbols, $\mathrm{FP}+1 \mathrm{mM}$ putrescine; right hand column, $\mathrm{FP}+5 \mathrm{mM}$ putrescine.

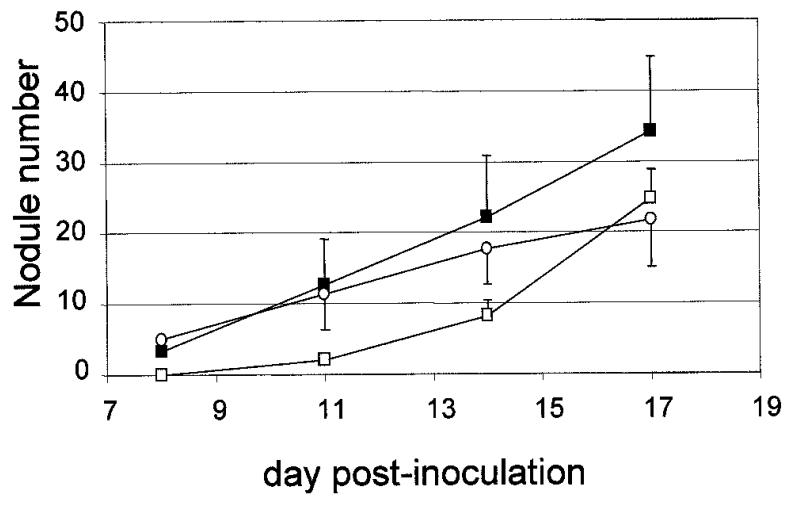

Fig. 7. Nodule number induced by lipopolysaccharide (LPS)-deficient Rhizobium strain B661, related to time. Filled squares, wild type (WT); circles, AS 2.6; open squares, S2.10.
(Wisniewski et al. 2000). Using the same assay for MGP extractability that was used in the previous study, we analyzed the release of MGP from transgenic pea root tips following a soaking for $5 \mathrm{~min}$ with $20 \mathrm{mM}$ putrescine. Results in Figure 9 show that the release of MGP from transgenic co-suppressed lines was greater than in the case of the WT or AS lines. This result confirms previous indications that DAO was involved in reducing the extractability of MGP from root tips.

\section{DISCUSSION}

There is increasing evidence that DAO may be implicated in plant growth and development as well as in response to environmental stress. As an apoplastic $\mathrm{H}_{2} \mathrm{O}_{2}$-generating enzyme, DAO may act together with peroxidases to mediate protein cross-linking and lignin deposition in plant cell walls experiencing physical or physiological stress. In addition, DAO may serve to modify tissue levels of putrescine (or of other diamines) and hence it could influence PA metabolism in the host plant.

Using a root tip secretion system (Wisniewski et al. 2000), we have recently demonstrated that MGP, a component of infection threads, can be insolubilized by DAO activity and that putrescine is the preferred substrate for this peroxide-driven, cross-linking reaction. Such an activity could serve to restrict the growth of rhizobia within infection threads and increase the stringency of the host-defense response that operates
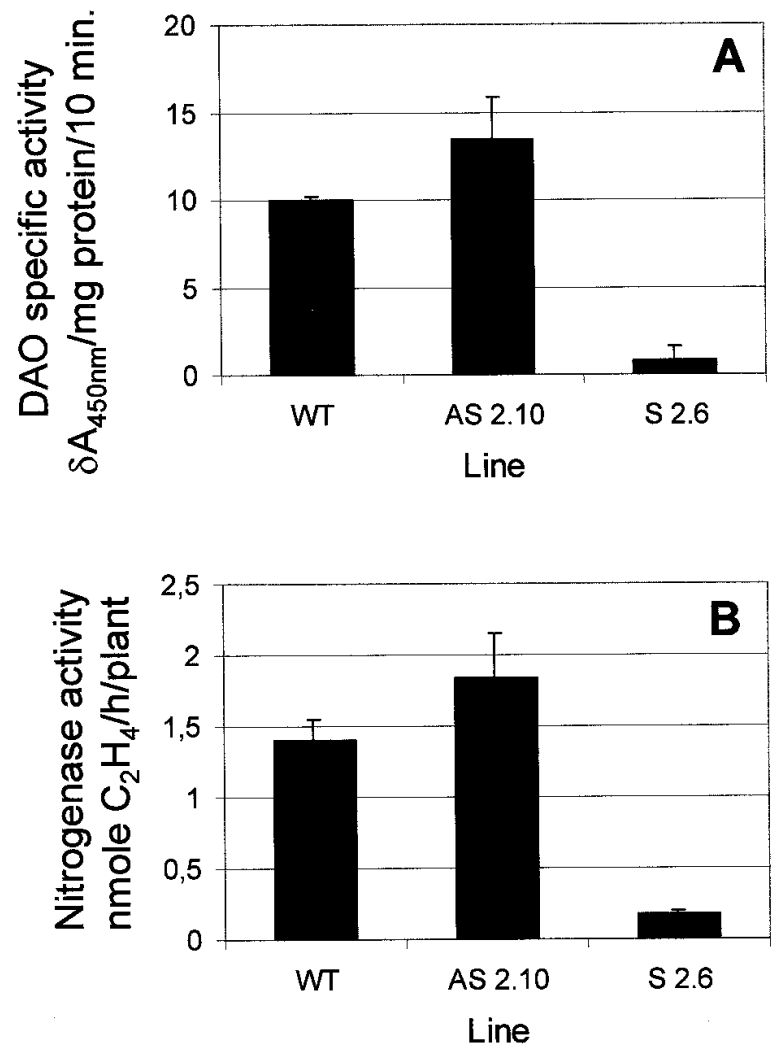

Fig. 8. Diamine oxidase (DAO)-specific activity and acetylene reduction activity in nodules induced by lipopolysaccharide (LPS)-deficient strain B661. A, Quantification of specific activity of DAO in nodules. B, Acetylene reduction activity quantified at 17 days post inoculation. 
against symbiotically defective (e.g., LPS-defective) rhizobia (Perotto et al. 1994). From this hypothesis, it might be predicted that DAO-suppressed pea lines would show enhanced nodulation, particularly with LPS-defective mutants. Furthermore, pea lines over-expressing DAO might be expected to show a reduced capacity for nodulation.

To investigate the role of DAO during pea root colonization by Rhizobium spp., we generated transgenic pea lines that showed modified levels of enzyme activity. We used a PsENOD12A promoter with the intention of confining our studies to the invasion zone of the nodule (Vijn et al. 1995). However, these AS constructs yielded no detectable change in DAO activity whatever the tissue or the line analyzed. Similarly, the $\mathrm{S}$ constructs did not result in over-expression of DAO. On the contrary, two $\mathrm{S}$ lines were obtained in which DAO activity was decreased in all regions of the plant and by up to $90 \%$ in nodules, apparently through the phenomenon of co-suppression (Hamilton and Balcombe 1999; Kooter et al. 1999). In standard growth conditions, neither nodule number nor nitrogen fixation ability was affected in these co-suppressed lines, indicating that DAO activity was not essential for nodule development under these conditions. Furthermore, the nodulation phenotype with LPS mutants was even more severe than with control lines. Therefore, we conclude that DAO did not have a controlling influence on nodule initiation under these conditions (Bouchereau et al. 1999; Kumar et al. 1997).

The situation was somewhat different after the addition of exogenous putrescine. We showed that supplying peas with exogenous putrescine, the main diamine found in pea (Fujihara et al. 1994), modified the nodulation capacity of the plants. With low concentrations of putrescine, a slight increase in nodule number was observed and significant differences in nitrogen fixation capacity were detected. Indeed, the acetylene reduction activity of nodulated roots was increased by $50 \%$ in the presence of $100 \mu \mathrm{M}$ exogenous putrescine while, with 1 $\mathrm{mM}$, a strong diminution was quantified (Fig. 5). A similar result was previously obtained with Galega orientalis (Vassileva and Ignatov 1999) and it has also been shown that PAs modulate the growth of Bradyrhizobium japonicum bacteroids in soybean nodules (Ozawa and Tsuji 1993). It is thus possible that putrescine affects the development and the growth of bacteroids in developing nodules. Alternatively, the excess of putrescine could trigger an oxidative stress mediated by the action of DAO or by induction of an oxidative burst, as sug-

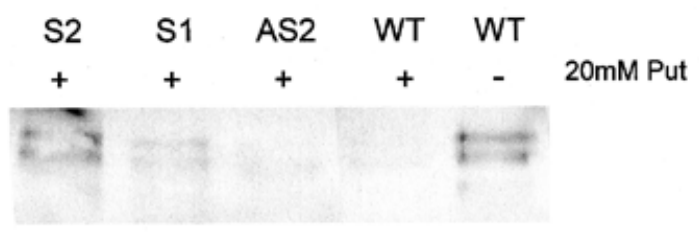

Fig. 9. Western blot (immunoblot) analysis of matrix glycoprotein (MGP) release from transgenic pea root tips. Seedlings used were from the $\mathrm{T}_{2}$ generation (i.e., progeny from plants $\mathrm{S} 2.10, \mathrm{~S} 1.10$, and AS2.6, respectively). Six transgenic or wild-type (WT) pea seedlings (4 days old) were soaked for $5 \mathrm{~min}$ in a microcentrifuge tube containing $20 \mathrm{mM}$ putrescine or no putrescine (control), washed briefly, and soaked in an extraction buffer for $30 \mathrm{~min}$. The release of MGP from root tips was then analyzed after sodium dodecyl sulfate-polyacrylamide gel electrophoresis (SDS-PAGE) and blotting of the samples $(0.5 \mu \mathrm{g})$ with the monoclonal MAC265. gested by Allan and Fluhr (1997). These resulting oxidative conditions and subsequent induction of defense reactions might prevent root colonization by Rhizobium spp.

Feeding the transgenic plants with inhibitory levels of exogenous putrescine $(1 \mathrm{mM})$ indicated that DAO normally contributes to this inhibitory effect because the nodules of the $\mathrm{S}$ co-suppressed lines were still $\mathrm{Fix}^{+}$whereas the WT and AS lines were Fix ${ }^{-}$(Fig. 6). Presumably, in the lines with normal DAO activity (WT or AS), the excess of putrescine would be oxidized by DAO, resulting in an increase of $\mathrm{H}_{2} \mathrm{O}_{2}$ production, whereas in the $\mathrm{S}$ lines (with reduced DAO activity) putrescine would be catabolized more slowly.

Similarly, it was shown that, in the co-suppressed lines with reduced DAO activity, MGP was more easily extractable from root tips following the application of putrescine (Fig. 9). We have argued elsewhere (Wisniewski et al. 2000) that in WT peas, impairment of MGP release is the consequence of DAOinduced liberation of $\mathrm{H}_{2} \mathrm{O}_{2}$, which serves to cross-link the MGP. Consequently, extensin becomes insoluble and nonextractable in the presence of putrescine. Furthermore, since MGP is a component of the infection thread lumen, crosslinking resulting from DAO-derived peroxide might be an important regulator of infection thread development.

The LPS-deficient strain B661, with impaired nitrogen fixation ability, induced poorly colonized nodules with a host defense reaction characterized by the accumulation of intercellular MGP (Perotto et al. 1994). Contrary to expectation, this strain induced a more extreme impairment of nodule development and nitrogen fixation capacity in the DAO cosuppressed lines. If the sole function of DAO were to promote cross-linking of the extracellular matrix, thereby activating the host defense response against inappropriate strains of Rhizobium, one might have predicted that lines with co-suppressed DAO activity would show an increased tolerance to incompatible Rhizobium strains, such as B661. On the contrary, the observation that DAO co-suppressed lines showed an even more intense reaction against the LPS-defective Rhizobium mutant suggests that a second effect of DAO may be operating, namely, to reduce endogenous levels of putrescine (which we have already shown to be inhibitory to nodule development). In this model, an incompatible strain, e.g., B661, might induce higher tissues levels of putrescine and PAs. In a WT plant, DAO would serve to catabolize putrescine, thereby reducing the concentration of PAs to a level that is not detrimental to nodule development. On the other hand, in the cosuppressed lines carrying strain B661, it is possible that induced putrescine accumulation in plant host cells could not be catabolized through the DAO pathway.

In conclusion, this study has established transgenic pea lines showing reduced levels of DAO. The properties of these cosuppressed lines indicate that DAO activity (at normal levels) is not essential for nodule development under normal conditions. In light of our original hypothesis that peroxide-driven crosslinking of infection thread glycoproteins may control the rate of infection thread growth, these results might indicate that DAO may be only one of several possible sources of hydrogen peroxide in the infection thread lumen. However, the co-suppressed lines do indicate that DAO is involved in mediating the inhibitory effect of exogenous putrescine on nodule development. Furthermore, there are indirect suggestions that DAO may serve to catabolize high levels of PAs induced during an incompatible 
interaction with an LPS-defective Rhizobium strain. The diverse roles for DAO that have been suggested by these transgenic experiments are consistent with the previously reported results from in situ hybridization, which showed that DAO transcript was expressed not only in the invasion zone but also in the central infected tissue of pea nodules (Wisniewski et al. 2000). Thus, the present study has highlighted the need for further investigations into the role of putrescine and other PAs in the regulation of legume nodule development.

\section{MATERIALS AND METHODS}

\section{S/AS DAO construct under the control of the PsENOD12A promoter.}

The pea PsENOD12A promoter (Vijn et al. 1995) was released from its original cloning vector, pIV20, by digestion with HindIII and SmaI. The insert DNA was ligated into the same sites of pJIT7 carrying the Cauliflower mosaic virus (CaMV) terminator, creating $\mathrm{pW} 1$. The HindIII site of $\mathrm{pW} 1$ was transformed into a ClaI site with the primer adapter $5^{\prime}$ AGCTATCGAT $3^{\prime}$ to create pW2. Digestion of pW2 with $B g l$ II followed by filling in the site with T4 polymerase created a ClaI site (pW3). The PSAO-1 cDNA (Tipping and McPherson 1995) was released from the Bluescript vector by digestion with NheI and NdeI. This 2.09-kb fragment, which contains the full coding sequence of DAO, was blunt ended and ligated into the SmaI site of $\mathrm{pW} 3$. Two new plasmids were created, pW4 carrying the AS DAO and pW6 carrying the S orientation. The full construct, comprising promoter/gene/terminator, was then inserted into the ClaI site of the binary vector E6/NOSBAR as shown in Figure 1. The pE6NOSBAR vector consists of pRK4-BglII (Bevan 1984) containing a 815-bp fragment made-up of $l a c Z^{\prime}$ and the pBlueScript polylinker flanked by synthetic left and right T-DNA borders based on pTiC58 (P. Mullineaux, personal communication).

\section{Agrobacterium-mediated pea transformation.}

The plasmids containing the S or AS construct were introduced into A. tumefaciens AGL1 (Lazo et al. 1991) for transfer into plants. Pea cultivar Puget was transformed according to Bean et al. (1997). Emerging shoots from cotyledonary meristems were selected on GB5 medium containing $3.5 \mathrm{mg}$ of phosphinothricin (PPT) per $\mathrm{ml}$ for 3 weeks post cocultivation, then containing $5 \mathrm{mg} / \mathrm{ml}$ for the remainder of the selection period. Resistant shoots $\left(\mathrm{T}_{0}\right)$ were then grafted with root-stock Puget seedlings (Schneider et al. 1999). Seeds from one such $\mathrm{T}_{0}$ plant (e.g., $\mathrm{S} 1$, carrying the $\mathrm{S}$ construct) were designated S1.1, S1.2, and so forth.

\section{PCR analysis of transgenic plants.}

DNA was extracted from single leaves of putative transformed plants according to Edwards et al. (1991). An aliquot $(5 \mu \mathrm{l})$ of this preparation was used as a template for PCR amplification of the introduced constructs. The primer Fe12 (GCGATACAACTTATCGTGTCTTTGTC) in the PsENOD12A promoter sequence was used in combination with primer RDOS-1 (AACAGAAAAAAGAGCAAGTCTC ATGG) to amplify the $S$ construct, or RDOA (ACTATT GAGCACCTCATTTGAGCTG) to amplify the AS construct. PCR was carried out for 30 cycles, each consisting of $30 \mathrm{~s}$ at $94^{\circ} \mathrm{C}, 40 \mathrm{~s}$ at $60^{\circ} \mathrm{C}$, and $30 \mathrm{~s}$ at $72^{\circ} \mathrm{C}$. Amplified DNA was separated by gel electrophoresis ( $1 \%$ agarose/1× TBE [Trisborate-EDTA]) and stained with ethidium bromide.

\section{Plant culture and inoculation.}

Pea seeds were surface sterilized with $70 \%$ (vol/vol) ethanol for $2 \mathrm{~min}$, followed by a commercial bleach solution for 12 min. After being rinsed with sterile water, they were germinated in a flask containing Fahraeus (FP) medium for 7 days at $20^{\circ} \mathrm{C}$ in the dark. Rhizobium leguminosarum bv. viciae 3841 or its LPS-deficient derivative strain B661 (Perotto et al. 1994) were cultured in TY medium. The 7-day-old seedlings were inoculated with $100 \mu \mathrm{l}$ of a 1:100 dilution of a bacterial suspension $\left(\mathrm{OD}_{600}\right.$ of 0.1$)$. For measurements of acetylene reduction activity, nodulated roots were tested 2 weeks post inoculation (Johnston and Beringer 1975). For the experiments implicating putrescine, the PA was added directly in the FP medium (Fahraeus 1957), prior to seed germination.

\section{Protein extraction.}

Samples of frozen tissues were individually ground to a fine powder with a mortar and pestle cooled with liquid nitrogen. The homogenates were extracted with $0.1 \mathrm{M}$ sodium phosphate buffer $(3 \mathrm{mg} / \mathrm{ml})$ containing a cocktail of protease inhibitors. After vigorous shaking, samples were centrifuged at $13,000 \times g$ for $10 \mathrm{~min}$. Protein concentration was determined by the BioRad assay system with bovine serum albumin (BSA) as standard.

\section{Electrophoresis and Western blot (immunoblot) analysis.}

Native polyacrylamide discontinuous gel (10\% wt/vol) electrophoresis was performed as described previously (Wisniewski et al. 2000). Proteins were transferred electrophoretically to nitrocellulose membrane (Schleicher and Schuell, Dassel, Germany), and the blots were blocked for $20 \mathrm{~min}$ in $1 \% \mathrm{BSA}(\mathrm{wt} / \mathrm{vol})$ in a solution containing Tris-buffered saline (TBS; $50 \mathrm{mM}$ Tris-HCl buffer pH 7.4 with $200 \mathrm{mM} \mathrm{NaCl}$ ). Blots were then incubated for $2 \mathrm{~h}$ with the monoclonal rat IgG antibody LM4, with the hybridoma cell culture supernatant at a dilution of 1:200 in blocking solution. LM4 was kindly provided by Paul Knox (University of Leeds), and its preparation is described elsewhere (Wisniewski et al. 2000). After several washing steps in TBS, the blots were incubated for $2 \mathrm{~h}$ with a goat alkaline phosphatase-conjugated anti-rat $\mathrm{IgG}$ secondary antibody (Sigma, Poole, UK; dilution 1:5,000). Another set of washes in TBS was performed followed by the detection of the alkaline phosphatase with a substrate solution containing 5-bromo, 4-chloroindolyl phosphate and nitroblue tetrazolium in Tris buffer (100 mM, pH 9.6, $1 \mathrm{mM} \mathrm{MgCl}_{2}$ ). All incubations were performed at room temperature.

\section{DAO enzyme assay.}

DAO activity was determined by the following method using a microtiter plate with 96 wells. To $100 \mu$ of the protein solution to be tested, $100 \mu \mathrm{l}$ of a cocktail containing the following was added: putrescine $20 \mathrm{mM}, 3,3^{\prime}, 5,5^{\prime}$-tetramethyl benzidine $0.1 \mathrm{mg} / \mathrm{ml}, 0.3 \mathrm{mU}$ HRP (Type I; Sigma) in $0.1 \mathrm{M}$ sodium acetate solution. After $10 \mathrm{~min}, 50 \mu \mathrm{H}_{2} \mathrm{SO}_{4}(1 \mathrm{M})$ was added to stop the reaction, and $A_{450}$ was estimated. Specific activity was then calculated by subtracting the $A_{450}$ obtained in the presence of $2 \mathrm{mM}$ of $o$-phenanthroline (Sigma), a specific DAO inhibitor. 


\section{RNA extraction and RT-PCR analysis.}

Total RNA was isolated according to de Vries et al. (1982) followed by a DNase I (GibcoBRL, Basingstoke, UK) treatment. A preparation of cDNA was made from $3 \mu \mathrm{g}$ of total RNA in a volume of $20 \mu$ containing Tris- $\mathrm{HCl}(10 \mathrm{mM}, \mathrm{pH}$ $8.8), \mathrm{KCl}(50 \mathrm{mM}), \mathrm{MgCl}_{2}(5 \mathrm{mM}), \mathrm{dNTPs}(1 \mathrm{mM}), 0.5 \mu \mathrm{g}$ of oligo-dT (T16), dithiothreitol (DTT; $10 \mathrm{mM}$ ), and reverse transcriptase (RT) Superscript (200 U, GibcoBRL) for $1 \mathrm{~h}$ at $42^{\circ} \mathrm{C}$ followed by $15 \mathrm{~min}$ at $70^{\circ} \mathrm{C}$. RNA was removed by adding $1 \mathrm{U}$ of RNase $\mathrm{H}$ for $20 \mathrm{~min}$ at $37^{\circ} \mathrm{C}$. The RT samples were then diluted to $120 \mu \mathrm{l}$. The PCRs were performed with 5 $\mu \mathrm{l}$ of the cDNA solution in Tris- $\mathrm{HCl}(10 \mathrm{mM}, \mathrm{pH} 8.3), \mathrm{KCl}$ (50 mM), $\mathrm{MgCl}_{2}(2.5 \mathrm{mM})$, dNTPs $(100 \mu \mathrm{M}), 50 \mathrm{ng}$ of primers, and 1 U Taq polymerase (Perkin Elmer, Beaconsfild, UK) in a total volume of $25 \mu \mathrm{l}$. PSAO-1 and ubiquitin were amplified with the PCR program $30 \mathrm{~s}$ at $94^{\circ} \mathrm{C}, 40 \mathrm{~s}$ at $60^{\circ} \mathrm{C}$, and 30 $\mathrm{s}$ at $72^{\circ} \mathrm{C}$. The following primers were used: PSAO-1f (CTCGAGATGGCTTCCACCACCACC), PSAO-1r (CTCTT CTCCAAACCAGCC), ubi-f (ATGCAGAT $/ \mathrm{T}$ TTTGGAA GAC) and ubi-r (ACCACCACG $\left./{ }_{A} A G A C G G A G\right)$. Under the conditions used, the amplification of ubi and PSAO-1 mRNA was exponential up to 30 cycles. After 28 cycles, the amplified DNA samples $(5 \mu \mathrm{l})$ were separated on a $1.2 \%$ agarose gel containing $1 \times \mathrm{TBE}$ and stained with ethidium bromide. The band intensity was quantified with Molecular Analyst software (BioRad, Hemel Hempstead, UK). All experiments were performed at least twice.

\section{ACKNOWLEDGMENTS}

We thank Phil Mullineaux for the transformation vector E6/NOSBAR; Ton Bisseling for the clone carrying the pENOD12A promoter; Mike McPherson for the cDNA clone for PsAO-1; Sam Bean for help with pea transformation; and A. Schneider and J. A. Downie for general discussions. We acknowledge support from the EU-TMR network "Symbiosis and Defence," no. ERBFMRX CT96-0039, and from the GB-BBSRC.

\section{LITERATURE CITED}

Allan, A. C., and Fluhr, R. 1997. Two distinct sources of elicited reactive oxygen species in tobacco epidermal cells. Plant Cell 9:1559-1572.

Angelini, R., Manes, F., and Federico, R. 1990. Spatial and functional correlation between diamine-oxidase and peroxidase-activities and their dependence upon deetiolation and wounding in chickpea stems. Planta 182:89-96.

Bean, S. J., Gooding, P. S., Mullineaux, P. M., and Davies, D. R. 1997. A simple system for pea transformation. Plant Cell Rep. 16:513-519.

Bevan, M. 1984. Binary Agrobacterium vectors for plant transformation. Nucleic Acids Res. 12:8711-8721

Bouchereau, A., Aziz, A., Larher, F., and Martin-Tanguy, J. 1999. Polyamines and environmental challenges: Recent developments. Plant Sci. 140:103-125.

Brewin, N. J., Rathbun, E. A., and Wisniewski, J.-P. 2000. Structure and development of infection threads. Pages 381-382 in: Nitrogen Fixation: From Molecules to Crop Productivity. F. E. Pedrosa, M. Hungria, M. G. Yates, and W. E. Newton, eds. Kluwer Academic Publishers, Dordrecht, The Netherlands.

de Vries, S. C., Springer, J., and Wessels, J. G. H. 1982. Diversity of abundant messenger-RNA sequences and patterns of protein synthesis in etiolated and green pea seedlings. Planta 156:129-135.

Edwards, K., Johnstone, C., and Thompson, C. 1991. A simple and rapid method for the preparation of plant genomic DNA for PCR analysis. Nucleic Acids Res. 19:134-135.

El Ghachtouli, N., Paynot, M., Martin-Tanguy, J., Morandi, D., and Gianinazzi, S. 1996. Effect of polyamines and polyamine biosynthesis inhibitors on spore germination and hyphal growth of Glomus mosseae. Mycol. Res. 100:597-600.
El Ghachtouli, N., Paynot, M., Morandi, D., Martin-Tanguy, J., and Gianinazzi, S. 1995. The effects of polyamines on endomycorrhizal infection of wild-type Pisum sativum, cv Frisson and $2 \mathrm{Nod}(-) \mathrm{Myc}(+)$ mutants. Mycorrhiza 5:189-192.

Fahraeus, G. 1957. The infection of clover root hairs by nodule bacteria studied by a simple glass technique. J. Gen. Microbiol. 16:374-381.

Flores, H. E. 1991. Changes in polyamine metabolism in response to abiotic stress. Pages 214-225 in: The Biochemistry and Physiology of Polyamines in Plants. R. Slocum and H. E. Flores, eds. CRC Press, Boca Raton, FL.

Fujihara, S., Abe, H., Minakawa, Y., Akao, S., and Yoneyama, T. 1994. Polyamines in nodules from various plant-microbe symbiotic associations. Plant Cell Physiol. 35:1127-1134.

Hamilton, A. J., and Baulcombe, D. C. 1999. A species of small antisense RNA in posttranscriptional gene silencing in plants. Science 286:950-952.

Johnston, A. W. B., and Beringer, J. E. 1975. Identification of the Rhizobium strains in pea root nodules using genetic markers. J. Gen. Microbiol. 87:343-350.

Kooter, J. M., Matzke, M. A., and Meyer, P. 1999. Listening to the silent genes: transgene silencing, gene regulation and pathogen control. Trends Plant Sci. 4:340-347.

Kumar, A., Altabella, T., Taylor, M. A., and Tiburcio, A. F. 1997. Recent advances in polyamine research. Trends Plant Sci. 2:124-130.

Lazo, G. R., Stein, P. A., and Ludwig, R. A. 1991. A DNA transformation-competent Arabidopsis genomic library in Agrobacterium. BioTechnology 9:963-967.

Maccarrone, M., Veldink, G. A., Vliegenthart, J. F. G., and Agro, A. F. 1997. Ozone stress modulates amine oxidase and lipoxygenase expression in lentil (Lens culinaris) seedlings. FEBS Lett. 408:241-244.

Medda, R., Padiglia, A., and Floris, G. 1995. Plant copper-amine oxidases. Phytochemistry 39:1-9.

Moller, S. G., and McPherson, M. J. 1998. Developmental expression and biochemical analysis of Arabidopsis ataol gene encoding an $\mathrm{H}_{2} \mathrm{O}_{2}$-generating diamine oxidase. Plant Cell 13:781-791.

Ozawa, T., and Tsuji, T. 1993. A possible role for polyamines in the repression of growth of Bradyrhizobium japonicum bacteroids in soybean nodules. Plant Cell Physiol. 34:899-904.

Perotto, S., Brewin, N. J., and Kannenberg, E. L. 1994. Cytological evidence for a host defense response that reduces cell and tissue invasion in pea nodules by lipopolysaccharide-defective mutants of Rhizobium leguminosarum strain 3841. Mol. Plant-Microbe Interact. 7:99-112.

Pinon, D., deArmas, R., Vicente, C., and Legaz, M. E. 1999. Role of polyamines in the infection of sugarcane buds by Ustilago scitaminea spores. Plant Physiol. Biochem. 37:57-64.

Schneider, A., Walker, S. A., Poyser, S., Sagan, M., Ellis, T. H. N., and Downie, J. A. 1999. Genetic mapping and functional analysis of a nodulation-defective mutant (sym19) of pea (Pisum sativum L). Mol. Gen. Genet. 262:1-11.

Smith, T. A., and Barker, J. H. A. 1988. The di- and polyamine oxidase of plants. Pages 573-587 in: Progress in Polyamine Research. V. Zappia and A. E. Pegg, eds. Plenum Press, New York.

Tipping, A. J., and McPherson, M. J. 1995. Cloning and molecular analysis of the pea seedling copper amine oxidase. J. Biol. Chem. 270:16939-16946.

Torrigiani, P., and Scoccianti, V. 1995. Regulation of cadaverine and putrescine levels in different organs of chick-pea seed and seedlings during germination. Physiol. Plant. 93:512-518.

Vassileva, V., and Ignatov, G. 1999. Effect of polyamines on dicarboxylate and oxygen uptake by symbiosomes and free bacteroids from Galega orientalis nodules. Symbiosis 27:59-71.

Vijn, I., Christiansen, H., Lauridsen, P., Kardailsky, I., Quandt, H. J., Broer, I., Drenth, J., Jensen, E. O., van Kammen, A., and Bisseling, T. 1995. A $200 \mathrm{bp}$ region of the pea ENOD12 promoter is sufficient for nodule-specific and nod factor-induced expression. Plant Mol. Biol. 28:1103-1110.

Ye, B., Muller, H. H., Zhang, J., and Gressell, J. 1997. Constitutively elevated levels of putrescine and putrescine generating enzymes correlated with oxidant stress resistance in Conyza canadensis and wheat. Plant Physiol. 115:1443-1451.

Wisniewski, J.-P., Rathbun, E. A., Knox, J. P., and Brewin, N. J. 2000. Involvement of diamine oxidase and peroxidase in insolubilization of the extracellular matrix: Implications for pea nodule initiation by Rhizobium leguminosarum. Mol. Plant Microbe Interact. 13:413-420. 